\title{
Investigation of CMOS Multiplexor SEL Sensitivity at Low Temperature
}

\author{
R.K, Mozhaev ${ }^{1,2}$, V.P. Lukashin ${ }^{1,2}$, D.S. Ukolov ${ }^{1}$, A.A. Pechenkin ${ }^{1,2}$ \\ ${ }^{1}$ National Research Nuclear University MEPHI (Moscow Engineering Physics Institute), Moscow \\ ${ }^{2}$ Specialized Electronic Systems (SPELS), Moscow, rkmozh@spels.ru
}

\begin{abstract}
The paper presents the data obtained during the study of CMOS multiplexors single-event effects sensitivity at ion accelerator and at laser SEE-simulation facility. A comparison of SEL rate at normal and low temperature is made.
\end{abstract}

Keywords - Single Event Effects, CMOS Multiplexor, laser SEE simulation technique, temperature dependence.

\section{INTRODUCTION}

The development relevance of infrared (IR) photodetector arrays of various formats, which are the basis of television / heat-vision systems, continues to grow. The bulky optomechanical (vacuum) photosensitive-systems are replaced by compact integrated circuits. Modern IR activepixel sensors (APS) provide high spatial and temperature resolution and are widely used in various branches of science and technology [1].

Modern APS systems consist of two main parts: a multielement photosensitive structure and a silicon readout circuit (multiplexer). A multiplexer (MUX) is an integrated circuit that reads obtained electrical signals which are a result of photoelectric conversion of incident infrared light in photosensitive elements of a focal plane array (FPA).

Multiplexers used to switch signals are based on CCD and MOS transistor. MOS switches have the following advantages over the CCD: higher fill factor, smaller values of control voltage, greater dynamic range, lower power consumption and heat dissipation. Silicon multiplexers usually operate at temperatures in the range $65-300 \mathrm{~K}$. CMOS technology is widely used in embedded systems, such as readout ICs of infrared image sensors [2, 3].

Spacecraft tracking and guidance systems are used to determine the launch orientation of a carrier or satellite during a space mission. The reliability of these systems is crucial, and the requirements for radiation hardness are unavoidable [4].

During space operation, even if electronic devices are exposed to temperatures up to $200 \mathrm{~K}$, IR systems operate at cryogenic temperatures (up to $50 \mathrm{~K}$ ). Such conditions are necessary to increase their performance. The effectiveness of these systems can be affected by factors of space environment such as absorbed dose (gamma-rays, electrons), structural damage (protons, neutrons) and single event effects from heavy charged particles (heavy ions, protons) [5]. This paper is dedicated to the study of SEE and associated effects on CMOS Multiplexor of IR image sensor.

For the space industry, the risk of SEE can be evaluated with radiation tests on simulation facilities $[6,7]$ capable of providing exposure to a beam of heavy ions or protons with characteristics similar to the space environment. The exposure to heavy particles can also be simulated by using a laser-based method, which can assess devices sensitivity to upsets and failures.

\section{DEVICE UNDER TEST}

The aim of the work is to study the sensitivity of the multiplexer of a two-spectral matrix unit, which is part of an infrared photodetector, to the effects and failures caused by heavy ions and high-energy protons typical to outer space.

One of the key components of an image sensor system multiplexer is an integrated circuit that reads electrical signals generated by photosensitive elements when exposed to incident light [2]. A general structure of the readout CMOS multiplexer circuit is presented in Figure 1 [8].

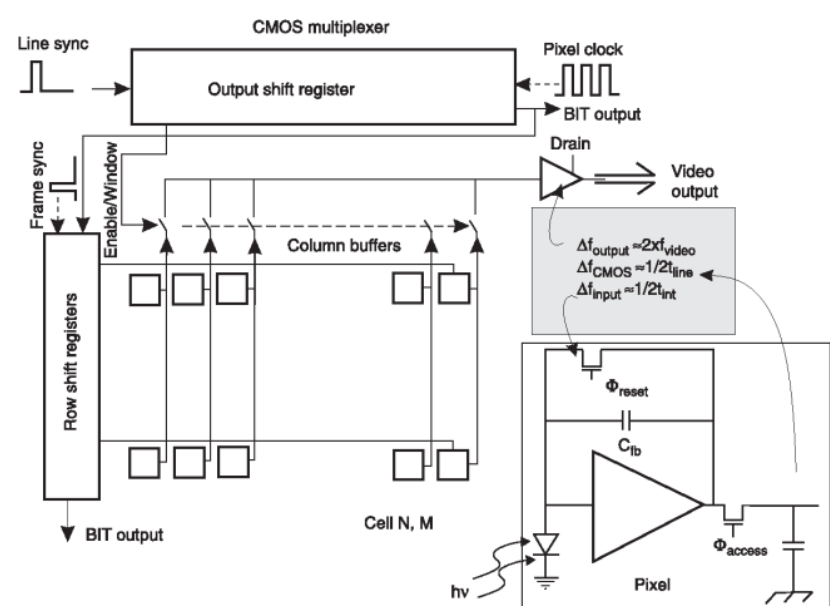

Fig. 1. CMOS multiplexing readout circuit scheme

The multiplexer consists of the following parts: a matrix of $\mathrm{M} \times \mathrm{N}$ read cells, horizontal and vertical registers, $\mathrm{M}$ read channels, an output amplifier. In each cell, a bias voltage VCM is set on the photodiode using an input transistor and to read the photocurrent. Photocurrent integrates on the storage capacity. When the addressing key (switch) is opened the accumulated charge is read by the sourcefollower amplifier. The subsequent charging of the 
capacitance is carried out with the help of a reset transistor. The received signals are multiplexed to the output using a horizontal register.

The considered matrix block consists of silicon CMOS ASIC, manufactured by "Micron" (Russia) for two-spectral APS blocks.

\section{DUT CONNECTION CIRCUIT}

In order to estimate devices suitability for space operations, it is necessary to evaluate its radiation hardness level. The connection diagram of DUT during irradiation is shown in Figure 2. During the radiation experiment, the following parameters of the product were monitored:

- Voltage at information outputs;

- Current consumption of the power circuit;

- Current consumption of secondary circuits.

The absence of upsets and failures was the criterion of devices normal operation. The threshold for recording of SEL was $45 \mathrm{~mA}$, and the current consumption limit was 50 $\mathrm{mA}$.

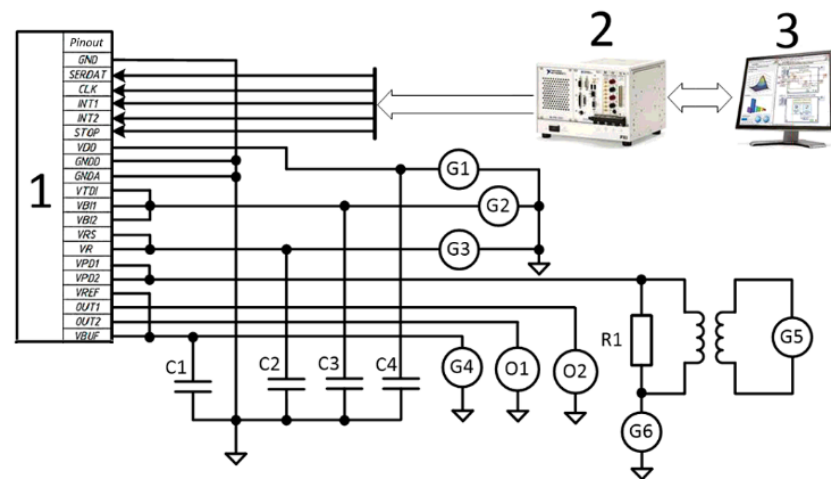

Fig. 2. MUX connection diagram during radiation tests

The multiplexer (labelled as 1 in Figure 2) parameters were monitored using the National Instruments hardwaresoftware complex (labelled as 2 in Figure 2) with programmable power supply module (G1-G6), a digitalanalog input-output module (FPGA), a signal generator module, and an oscilloscope module $(\mathrm{O} 1, \mathrm{O} 2)$ to control transient effects, $\mathrm{C} 1-\mathrm{C} 4$ are isolation tanks.

\section{EXPERIMENTAL SETUP}

The experimental data of device's irradiation at heavy ions cyclotron and at pulsed laser modulating facility in two temperature conditions is presented [9]. The results are described in the respective sections.

\section{A. Heavy Ions Irradiation}

The irradiation was carried out at heavy-ion cyclotron U-400M (JINR Dubna, Russia) with the following ions: argon (Ar), krypton ( $\mathrm{Kr})$, and xenon (Xe). The DUT was placed inside the vacuum chamber in a rotating frame. The ambient temperature during ion irradiation was $+25^{\circ} \mathrm{C}$. The parameters of test ions are given in Table 1. During irradiation, the samples were operated in dynamic mode: transmitting signal $(200 \mathrm{~Hz}, 3.3 \mathrm{~V})$ to a transformer with an offset. Every second the internal configuration registers we reflashed. The interval between registration of the thyristor effect (SEL) and its parry [9-11] was $50 \mathrm{~ms}$, time during which power supply was switched off after SEL registration was $100 \mathrm{~ms}$.

Table 1

Single event latch-up recording results after $\mathrm{Xe}, \mathrm{Kr}$, Ar ion irradiation

\begin{tabular}{|c|c|c|c|c|}
\hline $\begin{array}{c}\text { Ion LET, } \\
\mathrm{MeV} \cdot \mathrm{cm}^{2} / \mathrm{mg}\end{array}$ & $\begin{array}{c}\text { Sample } \\
\text { number }\end{array}$ & $\begin{array}{c}\text { SEL } \\
\text { amount }\end{array}$ & $\begin{array}{c}\text { Fluence, } \\
\mathrm{cm}^{-2}\end{array}$ & $\begin{array}{c}\text { SEL } \\
\mathrm{XS}, \\
\mathrm{cm}^{2}\end{array}$ \\
\hline \multirow{3}{*}{$67(\mathrm{Xe})$} & 1 & 112 & $2 \cdot 10^{6}$ & $\begin{array}{c}5 \mathrm{E}- \\
05\end{array}$ \\
\cline { 2 - 5 } & 2 & 110 & $4 \cdot 10^{6}$ & $\begin{array}{c}2 \mathrm{E}- \\
05\end{array}$ \\
\hline \multirow{3}{*}{$41(\mathrm{Kr})$} & 1 & 14 & $2 \cdot 10^{7}$ & $\begin{array}{c}6 \mathrm{E}- \\
07\end{array}$ \\
\cline { 2 - 5 } & 2 & 1 & $2 \cdot 10^{7}$ & $\begin{array}{c}7 \mathrm{E}- \\
08\end{array}$ \\
\hline \multirow{3}{*}{$18(\mathrm{Ar})$} & 2 & 0 & $3 \cdot 10^{7}$ & \multirow{2}{*}{$\leq 5 \mathrm{E}-$} \\
\cline { 2 - 4 } & 3 & 0 & $2 \cdot 10^{7}$ & 08 \\
\cline { 2 - 4 } & 4 & 0 & $2 \cdot 10^{7}$ & \multicolumn{2}{|c}{} \\
\hline
\end{tabular}

The current consumption level for the recording of SEL for each of the 4 channels was $45 \mathrm{~mA}$. When the product was irradiated with Xe and Krions, SEL were observed only through the VDD channel. Any destructive events or devices failures were not recorded during irradiation. The timing diagram reflecting the dynamics of the current and the parrying of the thyristor effect to the VDD channel of sample No. 1 is shown in Figure 3.

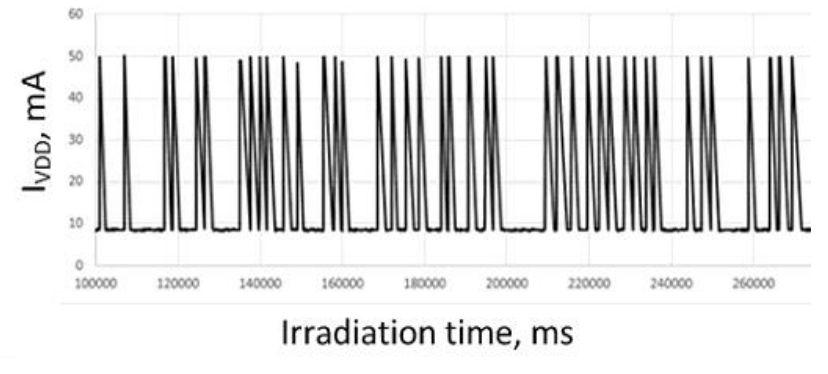

Fig. 3. Sample №1 current consumption monitoring results of the of VDD channel when exposed to Xe ion beam

The most adequate technique to estimate SEE sensitivity is based on heavy-ion accelerator tests, but it is rather expensive and time-consuming. In order to get complementary information, there is an alternative SEE simulation technique utilizing focused picosecond laser radiation [12-14] to trigger SEE events.

Subsequent identifying tests were carried out with a picosecond laser radiation simulator «PICO-4». More details on the testing features of this facility can be found in references [15-18]. 


\section{B. Laser SEE Simulation Facility}

There is an alternative way of SEE sensitivity estimation - the use of laser irradiation technique, which does not require a vacuum environment and provides more time and spatial information than traditional methods [12-14, 19].

The laser source of this facility has the following characteristics for wavelengths of $1.064 \mu \mathrm{m} / 0.532 \mu \mathrm{m}$, respectively:

- Pulse energy: 9,1 $\pm 0,5 / 2,7 \pm 0,2 \mu \mathrm{J}$;

- Relative output laser energy level setting deviation of built-in attenuator: 4,0\% / 7,4\%;

- Pulse duration: 70 ps / 70 ps;

- Focused spot diameter: $2,4 \mu \mathrm{m} / 1,8 \mu \mathrm{m}$;

SEE tests of microelectronic parts are usually carried out at normal and high temperatures. Common practice shows that the rate of single event effects at elevated temperature is significantly higher than at normal climatic conditions [9, 18]. In this case, since the product as part of its hardware unit which operates at low temperature, the tests were carried out at low temperature, which is much closer to its actual operating conditions.

The first step of laser tests was to scan the laser beam across the part, in order to localize SEL sensitive areas at a temperature of $+25^{\circ} \mathrm{C}$. From the many sensitive areas, the most critical ones are determined as the ones with the lowest threshold energy for SEL occurrence [15].

The second step was to scan the part, similar to step 1, but at a temperature of $-20^{\circ} \mathrm{C}$.

The exposure to laser radiation of a wavelength of 1.064 $\mu \mathrm{m}$ and duration of $70 \mathrm{ps}$ was carried out from the upper layer. The scanning step was $10 \mu \mathrm{m}$, the spot diameter was $20 \mu \mathrm{m}$, and the scanning area was $0.079 \mathrm{~cm}^{2}$. As with exposure to ions, the threshold for recording of SEL was 45 $\mathrm{mA}$, and the current consumption limit was $50 \mathrm{~mA}$.

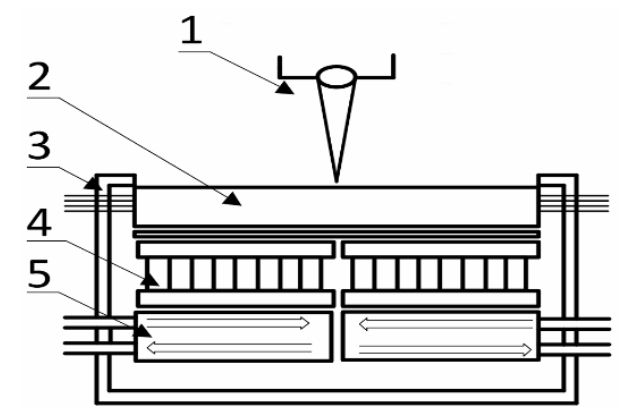

Fig. 4. General scheme of the applied multiplexer sample cooling system

There are various ways to set the product to a low temperature. The most common option is a liquid nitrogen evaporation control system. The difficulty of conducting tests at a low temperature on a laser facility is associated with such difficulties as the scattering of laser light on nitrogen vapor and the impossibility to place vapor nozzle in the immediate vicinity of a decapsulated sample. For these purposes, a compact cooling system was developed, and its block diagram is shown in Figure 4.

The laser source (1) is above the active area of the sample (2) located in the casing of the cooling system (3). A cascade of thermoelectric coolers (4) is used as cooling elements. Heat removal was carried out by placing the TEC "hot" side on copper heat sinks (5), with water heat removal tubes connected to them. This design made it possible to stably maintain a temperature of $-20^{\circ} \mathrm{C}$ for several hours long enough to conduct the laser scanning.

\section{RESUlts}

The results of the laser scanning, presented in Table 2, show that maintaining the device in a temperature regime close to its natural operation mode (i. e. low temperature) during exposure to a laser pulse, prevents SEL occurrence. Therefore, this mode of operation provides the device a significant resistance to the manifestation of SEL.

Table 2

The results of the MUX IC surface scanning in two temperature regimes

\begin{tabular}{|c|c|c|}
\hline $\begin{array}{c}\text { Ambient } \\
\text { (sample case) } \\
\text { temperature }\end{array}$ & $\begin{array}{c}\text { Laser Pulse Energy, } \\
\mathrm{nJ}\end{array}$ & $\begin{array}{c}\text { Amount of } \\
\text { registered } \\
\text { SEL }\end{array}$ \\
\hline \multirow{4}{*}{$+25^{\circ} \mathrm{C}$} & 150 & 1 \\
\cline { 2 - 3 } & 170 & 15 \\
\cline { 2 - 3 } & 200 & 156 \\
\cline { 2 - 3 } & 270 & 250 \\
\hline \multirow{2}{*}{$-20^{\circ} \mathrm{C}$} & 380 & 308 \\
\cline { 2 - 3 } & $<300$ & $\mathbf{0}$ \\
\hline
\end{tabular}

Tests of a similar CMOS multiplexer at an ion accelerator were carried out by a team of authors and described in [5]. According to their results, it was determined that when the product is irradiated in the mode that is closest to the natural (i. e. low temperature), the cross section of effects is significantly lower than in the normal climatic conditions. These results are consistent with the data obtained here and confirm the need for testing microelectronic products not only in general critical temperature conditions but also in the modes closest to the equipment operating modes.

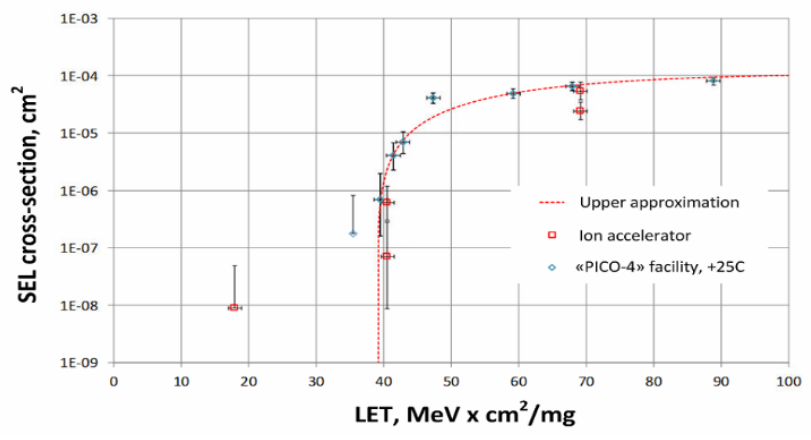

Fig. 5. Multiplexer test results (confidence probability $P=0.95$ ) 
Figure 5 presents the comparative results (SEL crosssection) of testing a multiplexer at a heavy-ion accelerator and at a laser facility at the same temperature conditions. From the consistency of the results, it can be assumed that, given the technical feasibility of conducting tests at lower temperatures at the cyclotron, we would get results that correlate with the data obtained at the laser facility.

\section{CONCLUSION}

Studies of a $0.35 \mu \mathrm{m}$ CMOS multiplexer sensitivity to SEE on the U-400M ion accelerator (JINR, Dubna, Russia) and the PICO-4 laser facility were conducted.

The product in the hardware unit operates at low temperatures. For this reason, tests of sensitivity to single event effects induced failures were not carried out at elevated temperatures, typical for microelectronic products, but at low temperatures, closer to the operating conditions for this device. A special chiller was developed to meet the testing needs of such a device at the laser facility at low temperature.

It is noted that when the tested products operate in temperature conditions closer to their application (i. e. low temperature) during irradiation, the cross-section of effects is much lower than under normal climatic conditions. In this condition, it is important to use an individual approach to setting a product regime during tests, taking into account the specificity of its operating conditions.

\section{REFERENCES}

[1] Holst GC, Lomheim TS (2007) CMOS/CCD Sensors and Camera Systems, Bellingham, Wash.; The International Society for Optical Engineering; JCD Publishing

[2] Janesick J, Andrews J, Elliott T (2006) Fundamental performance differences between CMOS and CCD imagers: Part I, Proc SPIE 6276:62760M-1-19

[3] Janesick J, Andrews J, Tower J, Grygon M, Elliott T, Cheng J, Lesser M, Pinter J(2007) Fundamental performance differences between CMOS and CCD imagers; Part II. Proc SPIE 6690:669003-1-23

[4] Kessarinskiy, Leonid N. et al. Authentication of electronics components for cyber-physical systems. IT Security (Russia), [S.1.], n. 3, p. 67-78, 2018. ISSN 2074-7136. Available at: . Date accessed: 28 aug. 2018. doi:http://dx.doi.org/10.26583/bit.2018.3.07.

[5] Art, Laurent et al. "Update of Single Event Effects Radiation Hardness Assurance of Readout Integrated Circuit of Infrared Image Sensors at Cryogenic Temperature." Sensors (Basel, Switzerland) vol. $18,7 \quad 2338.18$ Jul. 2018, doi: $10.3390 / \mathrm{s} 18072338$

[6] S.Buchner et al., "Laboratory Tests for Single-Event Effects", IEEE Trans. on Nucl. Sci., vol. 43, № 2, pp. 678-686, 1996.
[7] G.C. Messenger, M.S.Ash, "Single Event Phenomena", N.Y.: Chapman \& Hall, 368 pp., 1997.

[8] Rogalski, Antoni. "Optical Detectors for Focal Plane Arrays ." (2004).

[9] A.A.Pechenkin, A.N.Egorov, O.B.Mavritsky, S.V.Baranov, A.L.Vasil'ev, and A.V.Yanenko, "Estimating IC Susceptibility to Single-Event Latchup", Russian Microelectronics, vol. 37, № 1, pp. 41-46, 2008.

[10] P. J. Layton, ZEEE, D. R. Czajkowski, J. C. Marshall, H. F. D. Anthony and R. W. Boss IEEE Single Event Latchup Protection Of Integrated Circuits, RADECS 97. Fourth European Conference on Radiation and its Effects on Components and Systems (Cat. No.97TH8294) pp.327 - 331

[11] Pengwei Li, Xiaoyun Fu, Lei Luo, Qingkui Yu, A New Analyzing Method of Single Event Latch-Up Protection Circuit Based on Current Comparing and Its Performance Verification, Journal of Modern Physics, 2014, 5, 387-393

[12] A. I. Chumakov "Interrelation of Equivalent Values for Linear Losses of Energy of Heavy Charged Particles and the Energy of Focused Laser Radiation", Russian Microelectronics, vol. 40, № 3, pp. 149-155, 2011

[13] A. I. Chumakov, et al. Local Laser Irradiation Technique for SEE Testing of ICs. Proceedings of RADECS-2011, pp. 449453.

[14] A.N. Egorov "PICO-4" Single Event Effects Evaluation and Testing Facility Based on Wavelength Tunable Picosecond Laser. IEEE Radiation Effects DataWorkshop 2012, pp. 6972

[15] A.B. Boruzdina, A.A. Pechenkin, I.B.Yashanin, A. V. Ulanova, A. V. Yanenko, and A. I. Chumakov, "Method of SEU-hardness assurance for SRAM with error correction using focused laser sources," in Proc. 14 th European Conf. on Radiation and its Effects on Components and Systems, RADECS-2015, Moscow; Russian Federation; Sept. 14 -18, 2015, article number 7365632.

[16] D. V. Savchenkov, et al. "Study of SEL and SEU in SRAM using different laser techniques" in Proc. 14 th European Conf. on Radiation and its Effects on Components and Systems, RADECS-2013, Oxford; United Kingdom; Sept. 23 -27, article number 6937411.

[17] O. B.Mavritskii, A. I. Chumakov, A.N. Egorov, A.A. Pechenkin, and A.Y. Nikiforov "Laser equipment for hardness evaluation of semiconductor elements exposed to heavy charged particles (Review)", Instruments and Experimental Techniques, vol. 59, no. 5, pp. 627-649, 2016.

[18] Alexander A. Novikov et al. "SEE Laser Testing at Different Temperatures" 14 th European Conf. on Radiation and its Effects on Components and Systems, RADECS-2015, Moscow; Russian Federation; Sept. 14 -18, 2015

[19] Kastensmidt F. L., Tambara L., D. V. Bobrovsky, A. A. Pechenkin and A. Y. Nikiforov, "Laser testing methodology for diagnosing diverse soft errors I a nanoscale SRAM-based FPGA", IEEE Trans. Nucl. Sci., vol. 61, no. 6, pp. 331003137,2014. 


\title{
Исследование чувствительности КМОП-мультиплексора к тиристорному эффекту при пониженной температуре
}

\author{
Р.К. Можаев ${ }^{1,2}$, В.П. Лукашин ${ }^{1,2}$, Д.С. Уколов ${ }^{1}$, А.А. Печенкин ${ }^{1,2}$ \\ ${ }^{1}$ Национальный исследовательский ядерный университет «МИФИ», Москва \\ ${ }^{2} \mathrm{AO}$ «ЭНПО СПЭЛС», Москва, rkmozh@ spels.ru
}

\begin{abstract}
Аннотация - В работе представлены данные, полученные при исследовании чувствительности КМОПмультиплексоров к одиночным ядерным эффектам на ускорителе ионов и на моделирующей лазерной установке. Проведено сравнение числа зарегистрированных тиристорных эффектов при нормальной и пониженной температуре.
\end{abstract}

Ключевые слова - одиночные эффекты, тиристорный эффект, КМОП-мультиплексор, лазерная установка ПИКО-4, ускоритель ионов.

\section{СПИСОК ЛИТЕРАТУРЫ}

[1] Holst GC, Lomheim TS (2007) CMOS/CCD Sensors and Camera Systems, Bellingham, Wash.; The International Society for Optical Engineering; JCD Publishing

[2] Janesick J, Andrews J, Elliott T (2006) Fundamental performance differences between CMOS and CCD imagers: Part I, Proc SPIE 6276:62760M-1-19

[3] Janesick J, Andrews J, Tower J, Grygon M, Elliott T, Cheng J, Lesser M, Pinter J(2007) Fundamental performance differences between CMOS and CCD imagers; Part II. Proc SPIE 6690:669003-1-23

[4] Кессаринский, Леонид $\mathrm{H}$. et al. Идентификация элементной компонентной базы кибернетических систем. Безопасность информационных технологий, [S.1.], n. 3, p. 67-78, 2018. ISSN 2074-7136. Доступно на: . Дата доступа: $28 \quad$ aug. 2018 doi:http://dx.doi.org/10.26583/bit.2018.3.07

[5] Art, Laurent et al. "Update of Single Event Effects Radiation Hardness Assurance of Readout Integrated Circuit of Infrared Image Sensors at Cryogenic Temperature." Sensors (Basel, Switzerland) vol. 18,7 2338. 18 Jul. 2018, doi: $10.3390 / \mathrm{s} 18072338$

[6] S.Buchner et al., "Laboratory Tests for Single-Event Effects", IEEE Trans. on Nucl. Sci., vol. 43, № 2, pp. 678-686, 1996.

[7] G.C.Messenger, M.S.Ash, "Single Event Phenomena", N.Y.: Chapman \& Hall, 368 pp., 1997.

[8] Rogalski, Antoni. "Optical Detectors for Focal Plane Arrays ." (2004).

[9] A.A.Pechenkin, A.N.Egorov, O.B.Mavritsky, S.V.Baranov, A.L.Vasil'ev, and A.V.Yanenko, "Estimating IC Susceptibility to Single-Event Latchup", Russian Microelectronics, vol. 37, № 1, pp. 41-46, 2008.
[10] P. J. Layton, ZEEE, D. R. Czajkowski, J. C. Marshall, H. F. D. Anthony and R. W. Boss IEEE Single Event Latchup Protection Of Integrated Circuits, RADECS 97. Fourth European Conference on Radiation and its Effects on Components and Systems (Cat. No.97TH8294) pp.327 - 331

[11] Pengwei Li, Xiaoyun Fu, Lei Luo, Qingkui Yu, A New Analyzing Method of Single Event Latch-Up Protection Circuit Based on Current Comparing and Its Performance Verification, Journal of Modern Physics, 2014, 5, 387-393

[12] A. I. Chumakov "Interrelation of Equivalent Values for Linear Losses of Energy of Heavy Charged Particles and the Energy of Focused Laser Radiation", Russian Microelectronics, vol. 40, № 3, pp. 149-155, 2011

[13] A. I. Chumakov, et al. Local Laser Irradiation Technique for SEE Testing of ICs. Proceedings of RADECS-2011, pp. 449453.

[14] A.N. Egorov "PICO-4" Single Event Effects Evaluation and Testing Facility Based on Wavelength Tunable Picosecond Laser. IEEE Radiation Effects DataWorkshop 2012, pp. 6972

[15] A. B. Boruzdina, A. A. Pechenkin, I. B.Yashanin, A. V. Ulanova, A. V. Yanenko, and A. I. Chumakov, "Method of SEU-hardness assurance for SRAM with error correction using focused laser sources," in Proc. 14 th European Conf. on Radiation and its Effects on Components and Systems, RADECS-2015, Moscow; Russian Federation; Sept. 14 -18, 2015, article number 7365632.

[16] D. V. Savchenkov, et al. "Study of SEL and SEU in SRAM using different laser techniques" in Proc. 14 th European Conf. on Radiation and its Effects on Components and Systems, RADECS-2013, Oxford; United Kingdom; Sept. 23 -27 , article number 6937411 .

[17] O. B.Mavritskii, A. I. Chumakov, A.N. Egorov, A. A. Pechenkin, and A. Y. Nikiforov "Laser equipment for hardness evaluation of semiconductor elements exposed to heavy charged particles (Review)", Instruments and Experimental Techniques, vol. 59, no. 5, pp. 627-649, 2016.

[18] Alexander A. Novikov et al. "SEE Laser Testing at Different Temperatures" 14 th European Conf. on Radiation and its Effects on Components and Systems, RADECS-2015, Moscow; Russian Federation; Sept. 14 -18, 2015

[19] Kastensmidt F. L., Tambara L., D. V. Bobrovsky, A. A. Pechenkin and A. Y. Nikiforov, "Laser testing methodology for diagnosing diverse soft errors I a nanoscale SRAM-based FPGA", IEEE Trans. Nucl. Sci., vol. 61, no. 6, pp. 331003137,2014 . 